\title{
Haemophilia B curative FIX production from a low dose UCOE-based lentiviral vector following hepatic pre-natal delivery
}

Vincent Yu-cheng $\mathrm{KaO}^{1^{*}}$, Sonia Ferreira ${ }^{1^{*}}$, Simon $\mathrm{N}$ Waddington ${ }^{2,3}$ and Michael $\mathrm{N}$ Antoniou $^{1 \dagger}$

1. Gene Expression and Therapy Group, King's College London, Faculty of Life Sciences and Medicine, Department of Medical and Molecular Genetics, $8^{\text {th }}$ Floor Tower Wing, Guy's Hospital, London SE1 9RT, UK

2. Gene Transfer Technology Group, University College London, Institute for Woman's Health, 86-96 Chenies Mews, London WC1E 6HXZ, UK

3. Antiviral Gene Therapy Research Unit, Faculty of Health Sciences, University of the Witwatersrand, Johannesburg, South Africa.

* These authors contributed equally to this work.

† Corresponding author: michael.antoniou@kcl.ac.uk 


\section{Introduction}

Vectors based upon retroviruses remain the system of choice for achieving retention and function of therapeutic genes within a desired tissue, especially when targeting mitotic stem cell populations. Indeed, the use of gammaretroviral and lentiviral vectors have provided very encouraging positive results in clinical trials for a number of different conditions, particularly targeting the haematopoietic system for conditions such as severe immune deficiency (see Candotti, 2014; Cavazzana, 2014) and leukodystrophies (Cartier et al., 2009; Biffi et al., 2013). As part of this strategy, achieving reproducibility and stability of therapeutic gene expression remain essential components. This is especially the case in circumstances where no selective growth and survival advantage of corrected cells is expected (Antoniou et al., 2013).

A class of transcriptional regulatory element that has shown great promise at providing both reproducible and long-term stable transgene expression from within lentiviral vectors (LVs) is the ubiquitous chromatin opening element from the human CBX3-HNRPA2B1 housekeeping gene locus (A2UCOE). The prototypical A2UCOE fragment from this locus consists of a methylation-free $\mathrm{CpG}$ island encompassing the dual divergently transcribed $C B X 3$ and HNRPA2B1 promoters and is capable of negating transgene silencing even with integration events within centromeric heterochromatin (Antoniou et al., 2003, Williams et al., 2005). These properties argue that the A2UCOE possesses a dominant chromatin remodelling or opening function, which prevents transgene silencing through blocking the spread of heterochromatin and DNA methylation of the promoter driving transgene expression (Antoniou et al., 2003, Williams et al., 2005, Lindahl Allen and Antoniou, 2007).

More recently, the A2UCOE has been demonstrated to be highly efficacious within an LV context. The A2UCOE has been shown to provide stable function both in vitro and more importantly haematopoietic stem cells (HSCs) and their differentiated progeny in vivo from direct expression off the HNRPA2B1 promoter (Zhang et al., 2007 and 2010). In addition, an A2UCOE sub-fragment spanning the $C B X 3$ promoter alone has also been shown to provide stable expression albeit at much lower levels than that from the HNRPA2B1 promoter (MüllerKuller et al., 2015). The A2UCOE can also confer stability of expression on linked, silencingprone ubiquitous (Williams et al., 2005; Zhang et al., 2010; Pfaff et al., 2013; Phaltane et al., 2014) and tissue-specific (Brendel et al., 2012) promoters. Furthermore, A2UCOE-based LVs are the first to be shown to provide stability of expression in both embryonic and induced pluripotent stem cells and differentiated progeny of all three germ layers (Pfaff et al., 2013; Ackermann et al., 2014). The resistance to transcriptional silencing conferred by the A2UCOE is at least in part due to its ability to prevent DNA methylation of its own and linked heterologous promoters (Zhang et al., 2010; Brendel et al., 2012; Pfaff et al., 2013; Ackermann et al., 2014).

All evaluations to date of A2UCOE-based LV efficacy have been conducted in adult mouse model systems (Antoniou et al., 2013). An alternative gene therapy approach is that involving direct in vivo LV delivery to the developing fetus. Such prenatal gene therapy has a number of distinct advantages, especially when targeting stem cell populations such as HSCs including lower vector dose, targeting of rapidly expanding stem cell populations, inducing immune tolerance to the therapeutic gene product and ultimately prevention of disease onset that would normally occur either before or after birth (Coutelle and Waddington, 2012; Mattar et al., 2012; Loukogeorgakis and Flake, 2014). The fetal liver is the major haematopoietic organ at this stage of development and therefore the site of HSCs during gestation. Therefore 
therapeutic viral vectors delivered to the murine fetal liver pre-natally via yolk sac-associated blood vessels such as the vitelline duct, which joins the yolk sac to the midgut lumen of the developing fetus, are able to transduce not only hepatocytes but also HSC before the latter migrate to bone marrow. Thus long-term post-natal therapeutic benefit can potentially be achieved by the targeting of either or both of these organ systems.

We recently demonstrated that human fetal liver-derived HSCs are readily transducible with A2UCOE, PGK and EF1 $\alpha$ promoter-based LVs but with only the A2UCOE construct provided stable, long-term expression especially following transplantation into mice (Dighe et al., 2014). Here we extend these ex vivo studies by evaluating a series of A2UCOE reporter (eGFP, luciferase) gene and human coagulation factor IX (FIX) cDNA LVs following direct pre-natal delivery to the murine fetal liver. Our results show stable post-natal vector presence in both the liver and haematopoietic system with concomitant persistence of expression demonstrating efficient LV transduction of both fetal hepatocytes and HSCs. Most encouragingly, the A2UCOE-FIX construct, at a low (0.2) average vector copy number per liver cell, was able to provide stable levels of plasma FIXFIX productionwhich would convert severe haemophilia $B(<1 \%)$ to a mild phenotype $(\approx 20 \%)$. . Thus our results provide proof-ofprinciple for low dose pre-natal A2UCOE-based LV delivery to the liver as a therapeutic option for Haemophilia B and potentially other metabolic conditions.

\section{Materials and Methods}

\section{Lentiviral vector constructs}

The lentiviral vector (LV) containing an enhanced green fluorescent protein reporter gene under control of the $2.5 \mathrm{~kb}$ A2UCOE was in a standard HIV-1 based backbone with the U3 region within the 3'LTR deleted to render the construct self-inactivating (Zhang et al., 2007). The eGFP gene was followed by the woodchuck hepatitis virus post-transcriptional regulatory element (WPRE) to give the construct A2UCOE-eGFP-WPRE. Expression is driven off the HNRPA2B1 promoter of the A2UCOE (Antoniou et al., 2003; Zhang et al., 2007). The LV containing an A2UCOE-luciferase-WPRE cassette was kindly provided by Natalie Ward and Adrian Thrasher (Institute of Child Health, University College London, UK) and is as the A2UCOE-eGFP-WPRE vector but with the eGFP gene replaced with a $1.6 \mathrm{~kb}$ luciferase cDNA coding sequence. The A2UCOE-FIX-WPRE was within a pRRLSIN18 LV backbone (Follenzi et al., 2002) and consisted of a 2.2kb A2UCOE (Antoniou et al., 2003) driving expression of human FIX cDNA followed again by the WPRE. The SFFV-FIX-WPRE vector is as previously described and consists of the FIX cDNA transcribed from the spleen focus forming virus (SFFV) promoter-enhancer (Waddington et al., 2004).

\section{Lentiviral vector generation}

Stocks of HEK293T cells were maintained in Dulbecco's Modified Eagle Medium (DMEM) supplemented with $4500 \mathrm{mg} / \mathrm{l}$ L-anany-L-glutamine, $4.5 \mu \mathrm{g} / \mathrm{l}$ glucose, $10 \mu \mathrm{g} / \mathrm{ml}$ penicillin and streptomycin and $10 \%$ of fetal bovine serum (GE Healthcare Ltd, Chalfont St Giles, Buckinghamshire, UK). Cells were cultured at $37^{\circ} \mathrm{C}$ in a $5 \% \mathrm{CO}_{2}$ atmosphere within a NuaireDH Autoflow Air Jacketed $\mathrm{CO}_{2}$ incubator (Plymouth, Minnesota, USA). Lentiviral vector 
stocks were produced using standard methods by transient transfection of HEK293T cells as before (Talbot et al., 2010). Briefly, cells were grown to $70-80 \%$ confluence in $15 \mathrm{~cm}$ diameter Petri-dishes and transfected with a mixture of $50 \mu \mathrm{g}$ of transfer vector, $17 \mu \mathrm{g}$ of envelope (pMDG) and $32 \mu \mathrm{g}$ of packaging Gag/Pol (pCMVdR8.74) plasmids using polythylenimine (PEI, Sigma-Aldrich). Culture medium was replaced with $13 \mathrm{ml}$ fresh complete DMEM culture medium the next day and virus-containing culture supernatant harvested at $72 \mathrm{~h}$ and $96 \mathrm{~h}$ posttransfection. Virus was concentrated by centrifugation and resultant viral pellets resuspended in DMEM medium and stored in aliquots at $-80^{\circ} \mathrm{C}$.

\section{Lentiviral vector titration}

The titre of each concentrated LV stock was performed by transducing HEK293T cells and assaying for provirus at 3 days post-transduction by flow cytometry for eGFP reporter genebased vectors and by quantitative polymerase chain reaction (qPCR) for the FIX-containing LVs.

\section{Flow cytometry}

The percentage of eGFP positive cells was assessed by using a Becton Dickinson FACS Calibur (BD Biosciences; Franklin Lakes, New Jersey, USA) and CellQuest ${ }^{\mathrm{TM}}$ software (version 5.2.1; BD Biosciences, La Jolla, California, USA).

\section{Quantitative PCR ( $q P C R)$}

Determination of vector copy number per cell was by qPCR analysis of DNA from murine tissues or cultured cell DNA. Total genomic DNA from mouse tissues or 5-10 $\times 10^{6}$ tissue culture cells was isolated using the Promega Wizard ${ }^{\circledR}$ Genomic DNA purification kit (Promega UK, Southampton, UK), which was used in accordance with the manufacturer's instructions. Extracted DNA was diluted to a working concentration of 2-20ng/ $\mu$ l. The qPCR reactions were set-up in 96-well reaction plates (MicrpAmpTM Optical; Applied Biosystems, Forster City, California, USA) and reactions run in a 7900HT Fast Real Time PCR System (Applied Biosystems) instrument using Bushman's late reverse transcriptase (LRT) primer/probe set (Bushman et al., 2001). The LRT primers amplify the region of the HIV vector backbone between the right 5' LTR sequence and the 5' end of the gag gene such that only integrated DNA or proviral forms that have completed the two template switches of reverse transcription to double stranded DNA are detected. The sequences of Bushman's LRT primer sequences are as follows: LRT forward: 5' TGTGTGCCCGTCTGTTGTGT 3'; LRT reverse: 5' GAGTCCTGCGTCGAGAGAGC $\quad 3^{\prime} ; \quad$ LRT probe: $5^{\prime} \quad$ - $(F A M)$ CAGTGGCGCCCGAACAGGGA - (TAMRA) 3'. A clonal cell line with an independently determined viral copy number of one was used as a standard reference.

The endogenous human (GAPDH) or mouse (Gapdh) glyceraldehde-3-phosphate dehydrogenase gene was used to determine absolute numbers of genomes present in each qPCR reaction using the following primer/probe set to amplify the 5' end of exon V: GAPDH forward: 5' ACCACAGTCCATGCCATCACT 3'; Gapdh (mouse) reverse: 5' 
GGCCATCACGCCACAGCTT 3'; $\quad$ GAPDH $\quad$ probe: $5^{\prime} \quad$ - $\quad$ (FAM) CCACCCAGAAGACTGTGGATGGCC - (TAMRA) 3'.

The qPCR reactions employed the TaqMan Master Mix (PrimerDesign Ltd, Southampton, UK). The GAPDH and LRT reactions of each sample were run in duplicate and in parallel with standard reference samples. Quantification was conducted with Sequence Detection Systems software (SDS version 2.2.2 (A)Applied Biosystems, 2004) by reference to standard curves created by known copy number standard references. Viral copy number per genome was calculated by using Microsoft ${ }^{\circledR}$ Excel.

\section{Protein extraction}

Whole organs from mouse tissues were homogenised in $2 \mathrm{ml}$ of phosphate buffered saline (PBS), from which $500 \mu \mathrm{l}$ was taken for protein extraction in $500 \mu \mathrm{l}$ protein extraction solution (PBS containing $0.05 \%$ Tween $20^{\circledR}$ and $0.05 \%$ Triton X-100 [(v/v; Sigma-Aldrich Company Ltd, Poole, Dorset, UK)]. Tissue homogenates were centrifuged for 5 minutes at 13,000 rpm, supernatant collected and stored at $-20^{\circ} \mathrm{C}$ until use for protein analysis.

\section{FIXFIX enzyme linked immunosorbent assay (ELISA)}

Samples for analysis of FIX concentration were collected from mouse tissues (total protein), serum or cell culture supernatant. FIX ELISA was conducted using the Matched-Pair Antibody Set antigen kit (Affinity Biologicals ${ }^{\mathrm{TM}}$ Inc., Ancaster, Ontario, Canada) in accordance with the manufacturer's instructions.

\section{In vivo studies}

Work in vivo using wild type MF1 mice was conducted under United Kingdom Home Office regulations and was compliant with the guidelines of the Imperial College London and University College London ethical review committees.

Pre-natal delivery of LVs was by injection of a $20 \mu$ l volume containing $>1 \times 10^{9}$ viral particles per $\mathrm{ml}$ into each fetus via the yolk sac-associated vitelline vessel (Waddington et al., 2004) at either day 14 or 16 of gestation. The injected fetus was marked in utero, for post-partum identification, by injection of colloidal carbon into the flank $(>2 \mu \mathrm{l})$. A particular foot was tattooed again for identification after birth. Injected mice were bled via the tail vein every month postinjection and culled after 5-8 months for blood and organ analysis.

\section{In vivo bioluminescent imaging}

Mice were anesthetised with isoflurane using Boyle's apparatus, and injected intraperitoneally with $300 \mu \mathrm{L}$ of $15 \mathrm{mg} / \mathrm{mL}$ D-luciferin salt. Mice were left for 5 minutes exactly and then imaged for bioluminescence by the IVIS Imaging 50 Series system (Caliper Life Sciences Ltd, Runcorn, UK). After acquiring a gray-scale photograph a bioluminescence image was 
obtained with a 12-cm field of view, a binning (resolution) factor of 1 or 8 , and a $1 / f$ stop and open filter. Signal intensities were calculated with Living Image 2.50 software (Xenogen) and expressed as photons per second per centimetre squared per steradian (photons/second/cm2/sr).

\section{Results}

A2UCOE-based lentiviral vectors provide stable expression following pre-natal delivery to the liver

In order to establish proof-of-principle of pre-natal delivery to the fetal liver, we initially employed two lentiviral vector reporter gene constructs namely A2UCOE-eGFP (Figure 1A) and A2UCOE-lucifersase (Figure 2A).

Fetuses of wild-type MF1 strain mice $(n=9)$ were injected with $20 \mu l$ of the A2UCOE-eGFP vector at a concentration of $1 \times 10^{9} \mathrm{vp} / \mathrm{ml}$ via the yolk sac-associated vitelline duct at day 14 of gestation. All the mice were sacrificed at 150 days after birth for further analysis. Livers were isolated post-mortem and analysed by fluorescence microscope to detect any eGFP positive cells (Figure 1B). Bone marrow (BM) as well as spleen, lung and heart were also removed for determination of vector copy number (VCN) per genome using quantitative PCR (qPCR) (Figure 1C). All pre-natally injected animals showed normal tissue morphology compared to uninjected controls (data not shown).

Figure 1B shows three representative liver samples from injected fetuses observed by fluorescence microscopy. All three treated mice (UG-1, UG-2 and UG-3) showed a similar expression pattern of eGFP, while no eGFP positive cells were seen in the uninjected negative control mouse. The widespread and uniform punctuate fluorescent pattern suggested efficient pre-natal transduction of hepatocytes and clonal expansion of transduced cells.

Analysis of average VCN per genome revealed vector presence in liver, spleen and BM with values of 2.22, 0.55 and 0.95 respectively. Vector was undetectable in lung and heart tissues. As the fetal liver is also the site of haematopoiesis, these data demonstrate that the A2UCOEeGFP vector had also transduced haematopoietic stem cells (HSCs) with subsequent natural migration to BM post-natally. The higher $\mathrm{VCN}$ detected in the liver also suggests that hepatocytes are more readily transducible than fetal HSCs.

In order to allow monitoring of A2UCOE-based lentiviral vector expression within the liver over time in live animals, we next conducted a series of experiments with the A2UCOE-Luciferase construct (A2UCOE-Luc; Figure 2A).

As before fetuses of wild-type MF1 strain mice $(n=3)$ received $20 \mu$ of the vector preparation at a concentration of $1.32 \times 10^{9} \mathrm{vp} / \mathrm{ml}$ via the vitelline duct. Bioluminescence imaging was undertaken with live animals at 1 and 12 months after birth using the Xenogen system after intraperitoneal injection of luciferin (Figure 2B). All three animals injected with the A2UCOELuc vector showed strong bioluminescence in the area corresponding to the liver at one month of age (Figure 2B, upper panel) and which was maintained to the termination of the experiment at 12 months (Figure 2B, lower panel). Quantification of luminescence imaging of the luciferase transgene expression in liver gave an average radiance of $6.25 \times 10^{6}$ and $3.59 \times 10^{6}$ 
$\mathrm{p} / \mathrm{s} / \mathrm{cm}^{2} / \mathrm{sr}$ for the three treated mice at 1 and 12 months respectively (Figure 2C). Thus a decrease of luciferase transgene expression of 1.7-fold was observed between 1 and 12 months. Treated and control mice were sacrificed at 1 year of age for further analysis. Again $\mathrm{BM}$, spleen, lung and heart as well as liver were removed for quantification of average VCN per genome. The results (Figure 2D) show an average VCN of 2.36, 0.8 and 2.49 for liver, spleen and BM respectively. Thus in contrast to the data obtained with the A2UCOE-eGFP vector (Figure $1 \mathrm{C}$ ), the $\mathrm{VCN}$ in BM matched that of the liver. No vector was detected within either lung or heart tissues.

The average bioluminescence radiance per VCN of hepatocyte cells for the three treated mice was $1.41 \times 10^{6} \mathrm{p} / \mathrm{s} / \mathrm{cm}^{2} / \mathrm{sr}$ (Figure 2E). Protein extracts from BM or spleen were used to conduct luciferase assays and showed an average luciferase expression level per VCN for spleen and $\mathrm{BM}$ of $6.15 \times 10^{3}$ and $2.23 \times 10^{3} \mathrm{RLU} / \mathrm{ng}$ protein/VCN respectively (Figure $2 \mathrm{~F}$ ).

In summary, these results with the A2UCOE-eGFP and A2UCOE-Luc constructs show that pre-natal injection via the vitelline duct successfully and efficiently delivers lentiviral vectors to the fetal liver transducing both hepatocytes and HSCs.

Stable, Haemophilia B curative levels of human FIX production from an A2UCOE-based vector

The encouraging proof-of-principle data from the pre-natal delivery of A2UCOE-eGFP and A2UCOE-Luc LVs to the fetal liver (Figures 1 and 2), led us to investigate whether a similar approach could be employed with a therapeutic vector harbouring an A2UCOE-human factor 9 (A2UCOE-FIX) transgene (Figure 3A). A previously employed LV containing an FIX cDNA under control of the spleen focus forming virus promoter/enhancer (SFFV-FIX; Figure 3A), acted as a reference construct (Waddington et. al., 2004). The titres of the SFFV-FIX and A2UCOE-FIX vectors were quantified by qPCR at three days post-transduction of HEK293T or K562 cells and gave values of $1 \times 10^{10}$ and $8 \times 10^{8} \mathrm{vp} / \mathrm{ml}$ respectively.

For the SFFV-FIX group, fetuses of wild-type MF1 strain mice were injected with $20 \mu$ l of vector via the vitelline duct at day 16 of gestation ( $n=6$; SF1-SF-6). In the case of the A2UCOE-FIX, animals were injected at day 14 of gestation giving rise to three out of nine (UF1-UF3) being born for investigation.

Peripheral blood was collected at periodic intervals to quantify the plasma FIX concentration by ELISA at post-natal day 21, 60 and 150 for the SFFV-FIX group and 90, 150 and 210 days after birth for the A2UCOE-FIX animals. All animals for both vector groups were sacrificed at the final blood sample collection time point for molecular analysis of peripheral blood, plasma, $\mathrm{BM}$ and liver tissues.

The results from the SFFV-FIX injected animals showed that the concentration of plasma FIX rose significantly by 3 -fold from 1 to $3.55 \mu \mathrm{g} / \mathrm{mL}$ between post-natal days 21 and 150 (Figure $3 \mathrm{~B}$, top panels). For the A2UCOE-FIX group, the average concentration of plasma FIX was $1.74 \mu \mathrm{g} / \mathrm{mL}( \pm 0.36), 1.96 \mu \mathrm{g} / \mathrm{mL}( \pm 0.17)$ and $1.53 \mu \mathrm{g} / \mathrm{mL}( \pm 0.23)$ at 90,150 and 210 days after birth respectively. Thus transgene expression from the A2UCOE-FIX vector was stable and consistent throughout the 210 day period of the study (Figure 3B, lower panels). Of note is that both vector systems provided well in excess of the minimum $5 \%$ of normal plasma FIX values $(250 \mathrm{ng} / \mathrm{ml})$ required for therapeutic benefit. Indeed, the levels obtained are above the 
threshold of $20 \%$ normal values of FIX $(1.25 \mu \mathrm{g} / \mathrm{ml})$ recognized to be curative for Haemophilia B.

The animals of SFFV-FIX and A2UCOE-FIX vector groups were sacrificed at post-natal days 150 and 210 respectively for molecular analysis of the peripheral (white) blood cell (WBC) fraction, plasma, BM and liver tissues. Genomic DNA was analysed to determine average VCN per genome analysis by qPCR. The results show either a very low $0.12( \pm 0.13)$ and undetectable VCN per genome of the SFFV-FIX vector to be present in WBC and BM cells respectively (Figure 4A, top panel). For A2UCOE-FIX transduced group, there were no detectable vector sequences in either WBC or BM cells at the time of sacrifice. However, analysis of liver samples showed an average VCN per genome of $0.27( \pm 0.09)$ for the SFFVFIX group (Figure 4A) and $0.2( \pm 0.02)$ for the A2UCOE-FIX vector injected mice (Figure 4B).

The results we obtained with the A2UCOE reporter gene constructs (Figures 1 and 2) suggest that in all likelihood the primary source of circulating FIX was the liver. Therefore we next measured the FIX concentration in whole livers from both SFFV-FIX and A2UCOE-FIX mouse groups. Following homogenization of whole organs in $2 \mathrm{ml}$ of PBS and protein extraction, the amount of FIX was determined by ELISA. The results (Figure 4C) show that FIX production was on average $7.32( \pm 2.24) \mathrm{ng} / \mu \mathrm{g}$ protein/VCN in SFFV-FIX injected animals and 32.93 $( \pm 4.56) \mathrm{ng} / \mu \mathrm{g}$ protein/VCN for the A2UCOE-FIX group. Thus in conclusion, circulating levels of FIX were emanating from the liver and production from the A2UCOE-FIX cassette was approximately 4.5 fold higher per average VCN per genome than that obtained from the SFFVFIX construct.

\section{Discussion}

Although pre-natal viral gene therapy has attracted significant interest it has been hampered in terms of translation to the clinic by inefficient delivery, especially at acceptable doses and safety concerns, particularly inadvertent transduction of reproductive germ cells (Coutelle and Waddington, 2012; Mattar et al., 2012; Loukogeorgakis and Flake, 2014). Here we show that A2UCOE-based LVs can efficiently transduce the hepatocytes, and to a lesser degree the HSCs, of the murine fetal liver in vivo by delivery via the yolk sac-associated vitelline duct. The A2UCOE-based constructs were designed to drive expression of both reporter and FIX genes directly from the innate HNRPA2B1 promoter, which as in the case of targeting adult HSCs (Zhang et al., 2007), provided reproducible and stable transgene expression postnatally. Most encouragingly, we obtained stable Haemophilia B curative levels of FIX (at $20 \%$ of normal) in the plasma of injected mice at a low (0.18) average vector copy number per cell (Figures 3 and 4).

Although our results with the A2UCOE-eGFP and A2UCOE-Luc reporter gene constructs indicated that delivery of vector via the vitelline duct transduced both hepatocytes and HSCS (Figures 1 and 2), our analysis of A2UCOE-FIX and SFFV-FIX LV distribution between liver, peripheral blood and bone marrow post-natally detected vector only in liver, especially in the case of the animals administered with the with A2UCOE-FIX construct (Figures 4A and 4B). Thus we can conclude that the levels of plasma FIX seen in animals post-natally was essentially arising from secretion from the liver, as previously described (Waddington et al., 
2004). In addition, these results suggest that a relatively low amount of LV can be employed in pre-natal gene therapy to achieve high transduction efficiency of fetal hepatocytes to give a therapeutic level expression. Our data also implies that perhaps larger amounts of LV will be required to transduce HSCs in the murine fetal liver.

The SFFV-FIX LV construct used as a reference in the study presented here, has previously been shown to provide Haemophila B curative plasma levels of FIX in mice following direct pre-natal delivery of this viral vector (Waddington et al., 2004) and ex vivo transplanted HSCs following vector transduction (Bigger et al., 2006), albeit in the latter case at high average vector copy number per cell (greater than 10 in the majority of cell compartments analysed). However, given the demonstrated insertional mutagenesis potential of the SFFV element via its potent enhancer component (Stein et al., 2010), this promoter is no longer seen as viable option for inclusion within therapeutic LV cassettes. In our study the efficiency of expression from A2UCOE-FIX was comparable to that from the SFFV-FIX vector (Figures 3B and 3C) but at a lower average vector copy number per cell (Figures 4A and 4B). In addition, production of FIX per vector copy in liver was 4.5-fold higher from A2UCOE-FIX than SFFV-FIX (Figure 4C). Furthermore, A2UCOE efficacy of function at low LV copy number per cell coupled with a lack of classical enhancer function (Zhang et al., 2007) and engineering to eliminate aberrant splicing (Knight et al, 2012), combine to produce a low risk of insertional mutagenesis and thus, in principle, a high safety profile.

The results with the A2UCOE-hF.IX vector show that the A2UCOE was able to give stable and consistent transgene expression throughout a long period. A constant level of hF.IX production was produced over 7 months. The qPCR results of peripheral blood, bone marrow and liver cells showed that viral vectors were all integrated in hepatocytes rather than in HSCs as originally expected. The hF.IX ELISA of liver cells proved that hF.IX proteins were generated and secreted from the liver into circulation. The A2UCOE expression cassette was most potent giving high hF.IX production per viral vector copy $(32.93 \mu \mathrm{g} / \mathrm{VCN})$ into the circulation. Our data strongly suggest that therapeutic levels can be reached to cure Haemophilia B with low viral vector copy, thus, efficacy being achieved with a high safety

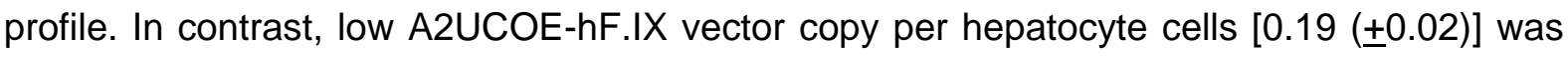
sufficient to give a therapeutic level of hF.IX production. Therefore, the efficacy and safety concerns in gene therapy are met with this UCOE-based vector system.

In summary, our results suggest that an in utero, pre-natal gene therapy approach can be used to efficiently target fetal liver at low A2UCOE-based LV doses of modest titre (minimum of $5 \times 10^{8} \mathrm{vp} / \mathrm{ml}$ ) and allow high, therapeutic transgene expressed at low average vector copy number per cell post-natally. Thus the approach we present here offers a viable alternative to high dose adeno-associated viral vector delivery to the liver for the treatment of Haemophilia B (High et al., 2014; Lheriteau et al., 2015) and other conditions that require targeting therapeutic gene deliver to this organ. 


\section{Acknowledgements}

We thank Natalie Ward and Adrian Thrasher for the A2UCOE-Luc vector. This work was funded in part by the UK Thalassaemia Society, who support is gratefully acknowledged. SNW received funding from the Katharine Dormandy Trust and from the ERC starting grant "Somabio".

\section{Conflicts of interest}

MNA hold inventor status on patents covering the biotechnological application of UCOEs. The other authors no conflicts of interest to declare.

\section{References}

Ackermann M, Lachmann N, Hartung S, Eggenschwiler R, Pfaff N, Happle C, Mucci A, Göhring G, Niemann H, Hansen G, Schambach A, Cantz T, Zweigerdt R and Moritz T (2014) Promoter and lineage independent anti-silencing activity of the A2 ubiquitous chromatin opening element for optimized human pluripotent stem cell-based gene therapy. Biomaterials, 35: 1531-1542.

Antoniou M, Harland L, Mustoe T, Williams S, Holdstock J, Yague E, Mulcahy T, Griffiths M, Edwards S, Ioannou PA, Mountain A and Crombie R (2003) Transgenes Encompassing Dual Promoter CpG Islands from the Human TBP and HNRPA2B1 Loci are Resistant to Heterochromatin-mediated Silencing. Genomics, 82: 269-279.

Antoniou MN, Skipper KA and Anakok O. (2013) Optimizing retroviral gene expression for effective therapies. Hum Gene Ther. 24: 363-374.

Biffi A, Montini E, Lorioli L, Cesani M, Fumagalli F, Plati T, Baldoli C, Martino S, Calabria A, Canale S, Benedicenti F, Vallanti G, Biasco L, Leo S, Kabbara N, Zanetti G, Rizzo WB, Mehta NA, Cicalese MP, Casiraghi M, Boelens JJ, Del Carro U, Dow DJ, Schmidt M, Assanelli A, Neduva V, Di Serio C, Stupka E, Gardner J, von Kalle C, Bordignon C, Ciceri F, Rovelli A, Roncarolo MG, Aiuti A, Sessa M and Naldini L. (2013) Lentiviral hematopoietic stem cell gene therapy benefits metachromatic leukodystrophy. Science, 341: 1233158.

Bigger BW, Siapati EK, Mistry A, Waddington SN, Nivsarkar MS, Jacobs L, Perrett R, Holder MV, Ridler C, Kemball-Cook G, Ali RR, Forbes SJ, Coutelle C,Wright N, Alison M, Thrasher AJ, Bonnet D, Themis M. (2006) Permanent partial phenotypic correction and tolerance in a mouse model of hemophilia B by stem cell genedelivery of human factor IX. Gene Ther., 13: $117-126$.

Brendel C, Müller-Kuller U, Schultze-Strasser S, Stein S, Chen-Wichmann L, Krattenmacher A, Kunkel H, Dillmann A, Antoniou MN and Grez M (2012) Physiological regulation of transgene expression by a lentiviral vector containing the A2UCOE CpG island fused to a myeloid promoter. Gene Ther., 19: 1018-1029.

Bushman FD, Butler SL and Hansen MS. (2001) A quantitative assay for HIV DNA integration in vivo. Nat Med, 7: 631-634. 
Cartier N, Hacein-Bey-Abina S, Bartholomae CC, Veres G, Schmidt M, Kutschera I, Vidaud M, Abel U, Dal-Cortivo L, Caccavelli L, Mahlaoui N, Kiermer V, Mittelstaedt D, Bellesme C, Lahlou N, Lefrère $F$, Blanche $S$, Audit $\mathrm{M}$, Payen $\mathrm{E}$, Leboulch $\mathrm{P}$, l'Homme $\mathrm{B}$, Bougnères $\mathrm{P}$, Von Kalle C, Fischer A, Cavazzana-Calvo M and Aubourg P. (2009) Hematopoietic stem cell gene therapy with a lentiviral vector in X-linked adrenoleukodystrophy. Science, 326: 818823.

Candotti F. (2014) Gene transfer into hematopoietic stem cells as treatment for primary immunodeficiency diseases. Int J Hematol., 99: 383-392

Cavazzana M. (2014) Hematopoietic Stem Cell Gene Therapy: Progress on the Clinical Front. Hum Gene Ther., 25: 165-170.

Coutelle C and Waddington SN. (2012) The concept of pre-natal gene therapy. Methods Mol Biol., 891: 1-7.

Dighe N, Khoury M, Mattar C, Chong M, Choolani M, Chen J, Antoniou MN and Chan JK. (2014) Long-term reproducible expression in human fetal liver hematopoietic stem cells with a UCOE-based lentiviral vector. PLoS One, 9(8): e104805.

Follenzi, A, Sabatino, G, Lombardo, A, Boccaccio, C and Naldini, L (2002). Efficient gene delivery and targeted expression to hepatocytes in vivo by improved lentiviral vectors. Hum Gene Ther., 13: 243-260.

High KH, Nathwani A, Spencer T, Lillicrap D (2014) Current status of haemophilia gene therapy. Haemophilia, Suppl 4: 43-49.

Knight S, Zhang F, Mueller-Kuller U, Bokhoven M, Gupta A, Broughton T, Sha S, Antoniou MN, Brendel C, Grez M, Thrasher AJ, Collins M and Takeuchi Y. (2012) Safer, silencingresistant lentiviral vectors: Optimization of ubiquitous chromatin opening element (UCOE) through elimination of aberrant splicing. J Virol., 86: 9088-9095.

Lheriteau E, Davidoff AM, Nathwani AC (2015) Haemophilia gene therapy: Progress and challenges. Blood Rev. pii: S0268-960X(15)00025-9.

Lindahl Allen $M$ and Antoniou M. (2007) Correlation of DNA methylation with histone modifications across the HNRPA2B1-CBX3 ubiquitously-acting chromatin open element (UCOE). Epigenetics, 2: 227-236.

Loukogeorgakis SP and Flake AW (2014) In utero stem cell and gene therapy: current status and future perspectives. Eur J Pediatr Surg., 24: 237-245.

Mattar CN, Waddington SN Biswas A, Davidoff AM, Choolani M, Chan JK and Nathwani AC (2012) The case for intrauterine gene therapy. Best Pract Res Clin Obstet Gynaecol. 26: 697709.

Müller-Kuller U, Ackermann M, Kolodziej S, Brendel C, Fritsch J, Lachmann N, Kunkel H, Lausen J, Schambach A, Moritz T, Grez M (2015) A minimal ubiquitous chromatin opening element (UCOE) effectively prevents silencing of juxtaposed heterologous promoters by epigenetic remodeling in multipotent and pluripotent stem cells. Nucleic Acids Res. 43: 15771592.

Pfaff N, Lachmann N, Ackermann M, Kohlscheen S, Brendel C, Maetzig T, Niemann H, Antoniou MN, Grez M, Schambach A, Cantz T, Moritz T. (2013) A ubiquitous chromatin 
opening element (UCOE) prevents transgene silencing in pluripotent stem cells and their differentiated progeny. Stem Cells, 31: 488-499.

Phaltane R, Lachmann N, Brennig S, Ackermann M, Modlich U, Moritz T (2014) Lentiviral MGMT(P140K)-mediated in vivo selection employing a ubiquitous chromatin opening element (A2UCOE) linked to a cellular promoter. Biomaterials, 35: 7204-7213.

Stein S, Ott MG, Schultze-Strasser S, Jauch A, Burwinkel B, Kinner A, Schmidt M, Krämer A, Schwäble J, Glimm H, Koehl U, Preiss C, Ball C, Martin H, Göhring G, Schwarzwaelder K, Hofmann WK, Karakaya K, Tchatchou S, Yang R, Reinecke P, Kühlcke K, Schlegelberger B, Thrasher AJ, Hoelzer D, Seger R, von Kalle C, Grez M (2010) Genomic instability and myelodysplasia with monosomy 7 consequent to EVI1 activation after gene therapy for chronic granulomatous disease. Nat Med., 16: 198-204.

Talbot GE, Waddington SN, Bales O, Tchen RC and Antoniou MN. (2010) Desmin-regulated Lentiviral Vectors for Skeletal Muscle Gene Transfer. Mol Ther., 18: 601-608.

Waddington SN, Nivsarkar MS, Mistry AR, Buckley SM, Kemball-Cook G, Mosley KL, Mitrophanous K, Radcliffe P, Holder MV, Brittan M, Georgiadis A, Al-Allaf F, Bigger BW, Gregory LG, Cook HT, Ali RR, Thrasher A, Tuddenham EG, Themis M and Coutelle C. (2004) Permanent phenotypic correction of hemophilia B in immunocompetent mice by prenatal gene therapy. Blood, 104: 2714-2721.

Williams, S., Mustoe, T., Mulcahy, T., Griffiths, M., Simpson, D., Antoniou, M., Irvine, A., Mountain, A. and Crombie, R. (2005) CpG-island fragments from the HNRPA2B1/CBX3 genomic locus reduce silencing and enhance transgene expression from the hCMV promoter/enhancer in mammalian cells BMC Biotechnology, 5: 17.

Zhang F, Frost AF, Blundell M, Bales O, Antoniou MN and Thrasher AJ (2010) A Ubiquitous chromatin opening element (UCOE) confers resistance to DNA methylation mediated silencing of lentiviral vectors. Mol Ther., 18: 1640-1649.

Zhang, F., Thornhill, S.I., Howe, S.J., Ulaganathan, M., Schambach, A., Sinclair, J., Kinnon, C., Gaspar, H.B., Antoniou M. and Thrasher, A.J. (2007) Lentiviral vectors containing an enhancer-less ubiquitously-acting chromatin opening element (UCOE) provide highly reproducible and stable transgene expression in haematopoietic cells. Blood, 110: 14481457. 
Figure 1

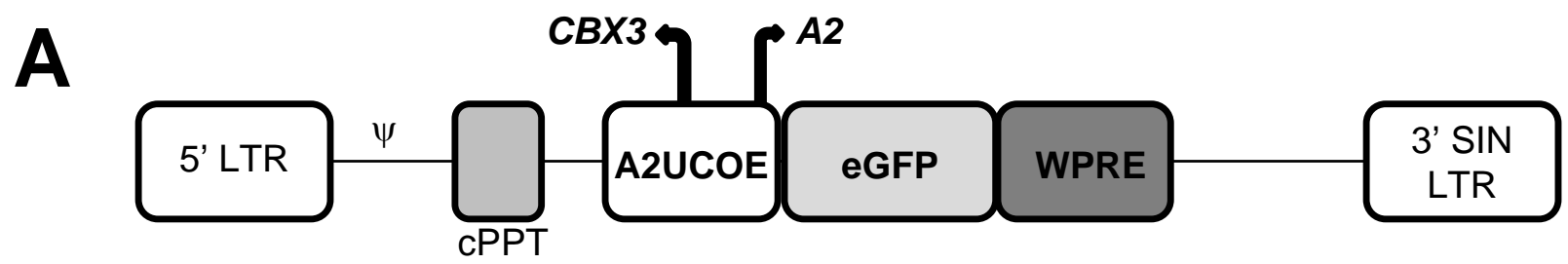

B

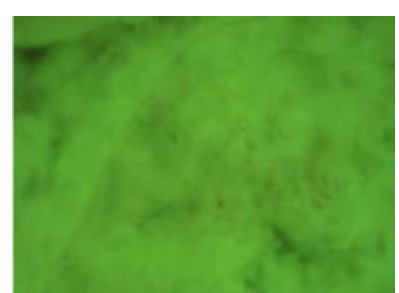

Negative

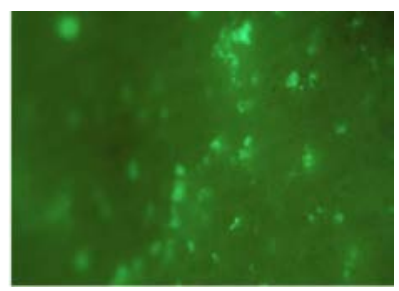

UG-2

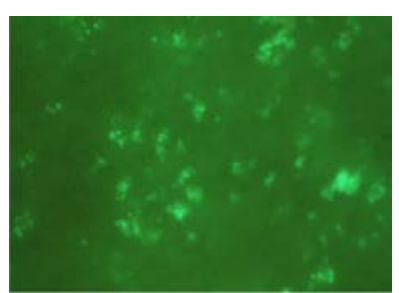

UG-1

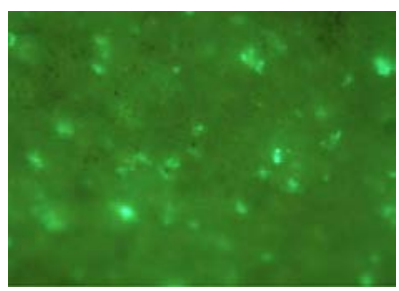

UG-3 
Figure 1

\begin{tabular}{c|ccccc} 
Mouse & Liver & Spleen & BM & Lung & Heart \\
\hline Negative & 0.00 & 0.00 & 0.00 & 0.00 & 0.00 \\
UG-1 & 2.58 & 0.53 & 0.90 & 0.00 & 0.00 \\
UG-2 & 2.15 & 0.13 & 1.32 & 0.00 & 0.00 \\
UG-3 & 2.76 & 0.24 & 0.48 & 0.00 & 0.00 \\
UG-4 & 2.02 & 0.51 & 0.62 & 0.00 & 0.00 \\
UG-5 & 1.53 & 0.95 & 0.47 & 0.00 & 0.00 \\
UG-6 & 2.16 & 0.75 & 1.59 & 0.00 & 0.00 \\
UG-7 & 1.93 & 0.47 & 1.59 & 0.00 & 0.00 \\
UG-8 & 2.35 & 0.52 & 0.59 & 0.00 & 0.00 \\
UG-9 & 2.47 & 0.83 & 1.02 & 0.00 & 0.00 \\
\hline Average & $\mathbf{2 . 2 2}$ & $\mathbf{0 . 5 5}$ & $\mathbf{0 . 9 5}$ & $\mathbf{0 . 0 0}$ & $\mathbf{0 . 0 0}$ \\
VCN & & & & &
\end{tabular}

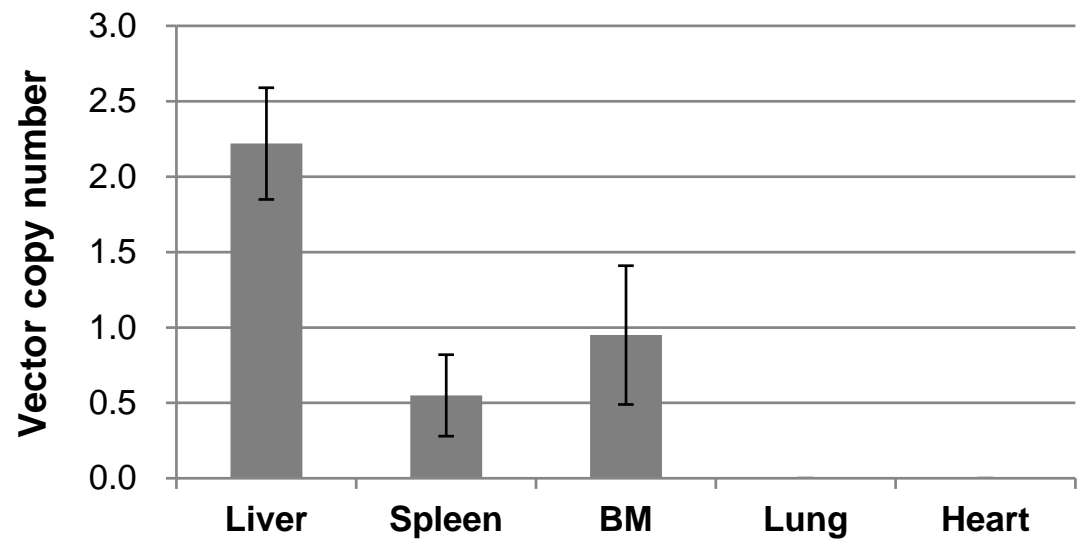

Tissues 
Figure 2

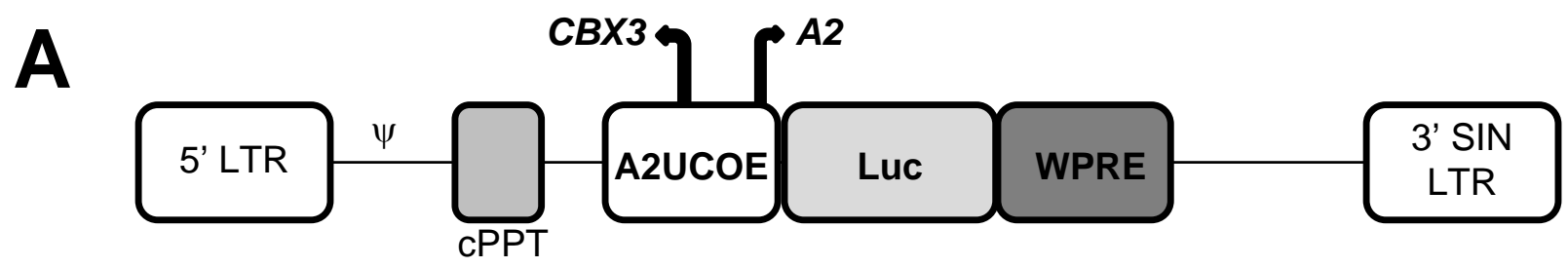

B

\section{1 month}

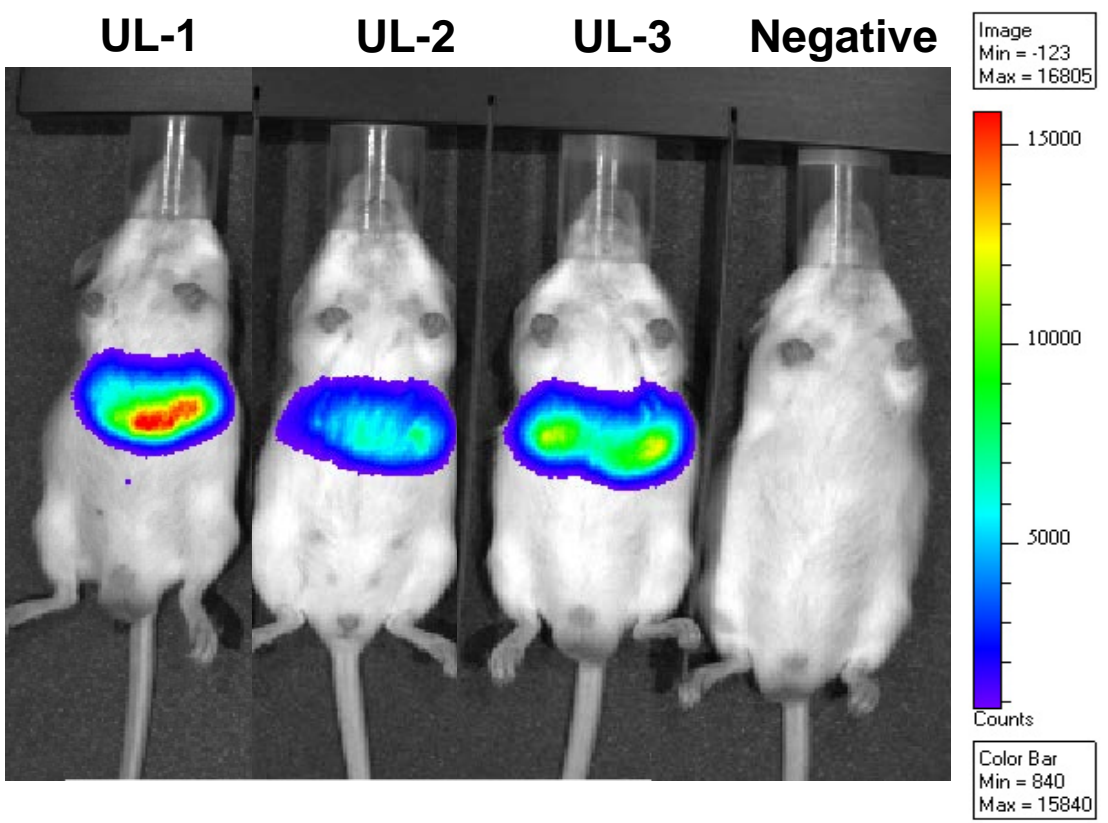

12 months

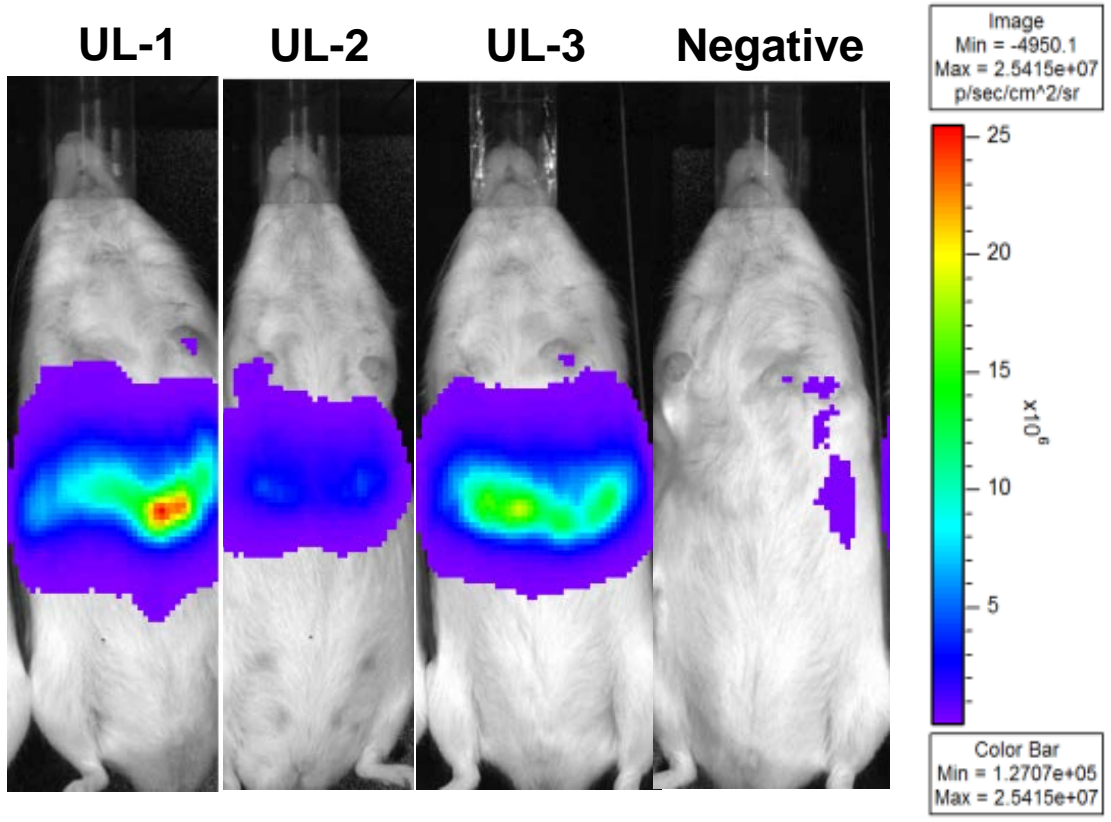


Figure 2

\begin{tabular}{c|cc} 
Mouse & $\mathbf{1}$ month & $\mathbf{1 2}$ months \\
\hline Negative & $9.65 \mathrm{E}+03$ & $5.03 \mathrm{E}+04$ \\
UL-1 & $8.11 \mathrm{E}+06$ & $5.08 \mathrm{E}+06$ \\
UL-2 & $3.86 \mathrm{E}+06$ & $1.07 \mathrm{E}+06$ \\
UL-3 & $6.79 \mathrm{E}+06$ & $4.61 \mathrm{E}+06$ \\
\hline $\begin{array}{c}\text { Average } \\
\text { radiance }\end{array}$ & $6.25 \mathrm{E}+06$ & $3.59 \mathrm{E}+06$
\end{tabular}

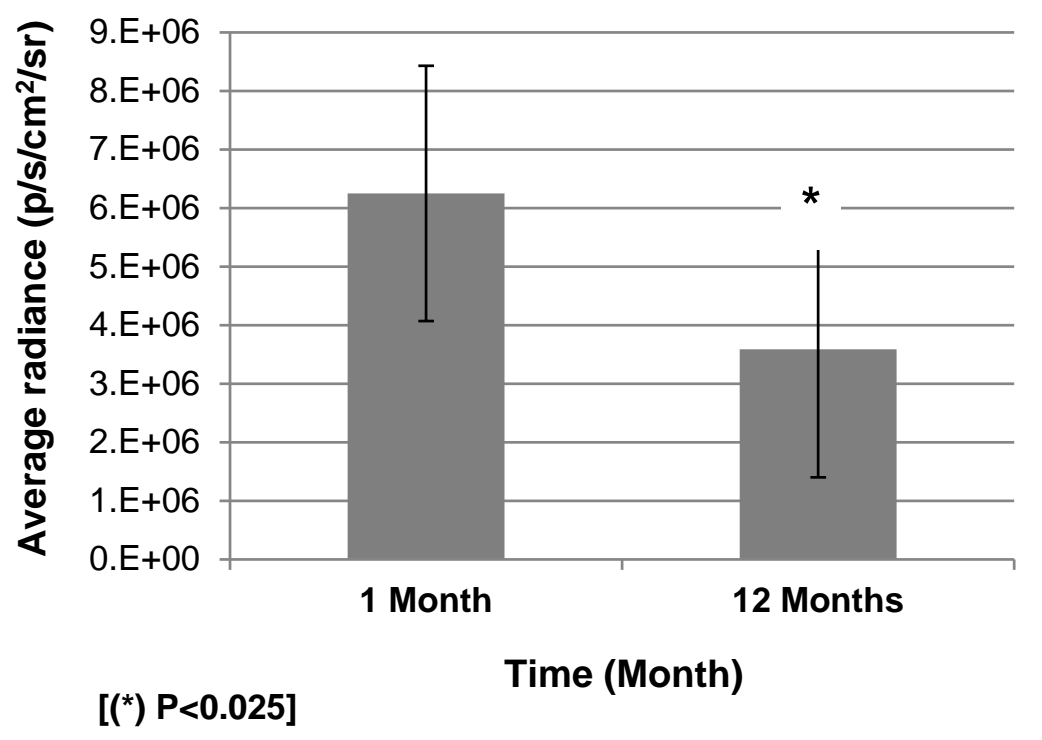

The numbers in the top panel should be in scientific notation i.e. $9.65 \times 10^{3}$ etc. Same for $y$-axis of lower panel 
Figure 2

\begin{tabular}{c|ccccc} 
Mouse & Liver & Spleen & BM & Lung & Heart \\
\hline Negative & 0.00 & 0.00 & 0.00 & 0.00 & 0.00 \\
UL-1 & 3.36 & 1.53 & 2.02 & 0.00 & 0.00 \\
UL-2 & 1.16 & 0.13 & 1.97 & 0.00 & 0.00 \\
UL-3 & 2.57 & 0.74 & 3.49 & 0.00 & 0.00 \\
\hline Average & $\mathbf{2 . 3 6}$ & $\mathbf{0 . 8 0}$ & $\mathbf{2 . 4 9}$ & $\mathbf{0 . 0 0}$ & $\mathbf{0 . 0 0}$ \\
VCN & & & & &
\end{tabular}

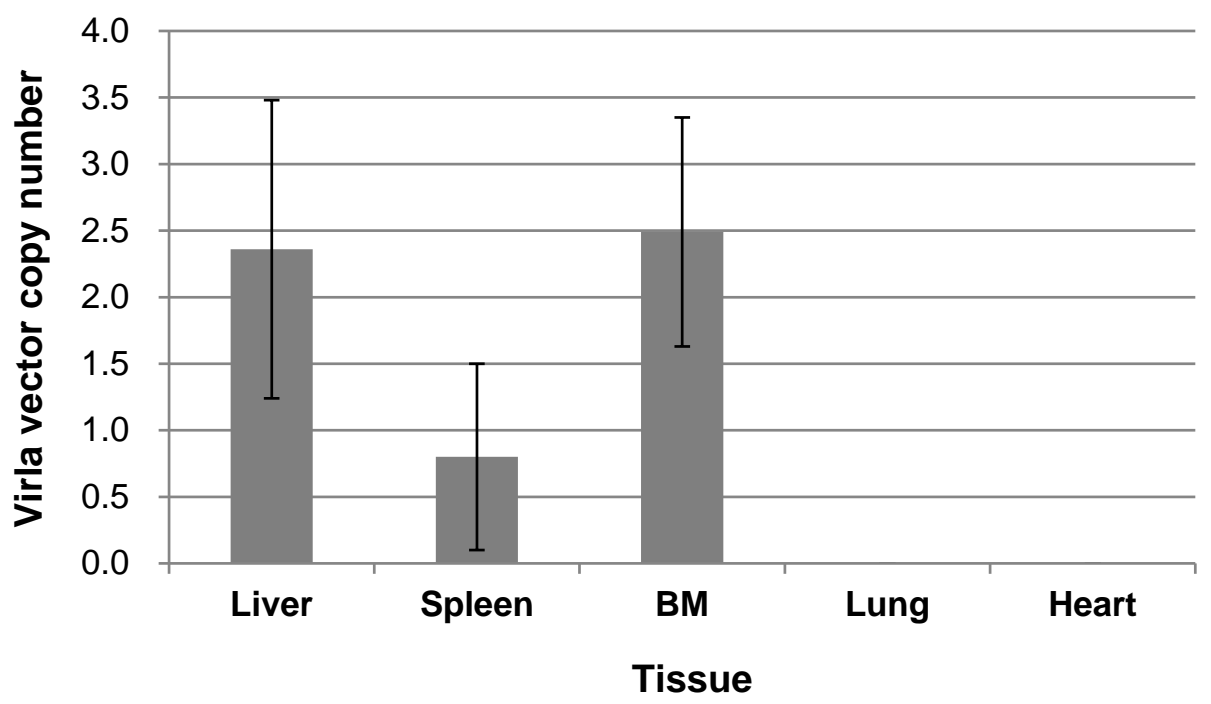

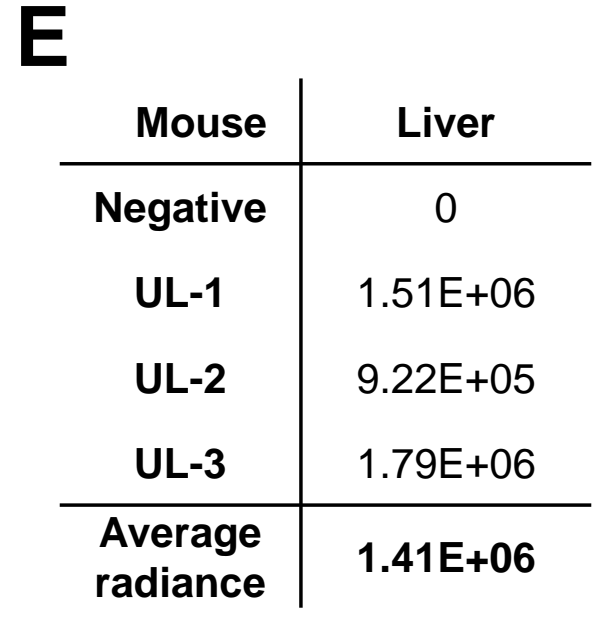

Scientific notation again for this table and graph y-axis

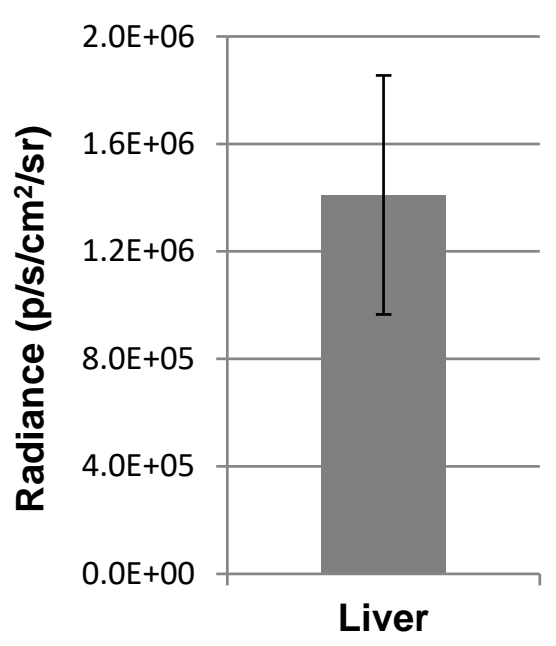

Liver 
Figure 2

\begin{tabular}{c|cc} 
Mouse & Spleen & BM \\
\hline UL-1 & $3.85 \mathrm{E}+02$ & $4.42 \mathrm{E}+03$ \\
UL-2 & $1.44 \mathrm{E}+04$ & $7.70 \mathrm{E}+02$ \\
UL-3 & $3.65 \mathrm{E}+03$ & $1.54 \mathrm{E}+03$ \\
\hline $\begin{array}{c}\text { Average } \\
\text { RLU/ng } \\
\text { protein/ } \\
\text { VCN }\end{array}$ & $6.15 \mathrm{E}+03$ & $2.24 \mathrm{E}+03$
\end{tabular}

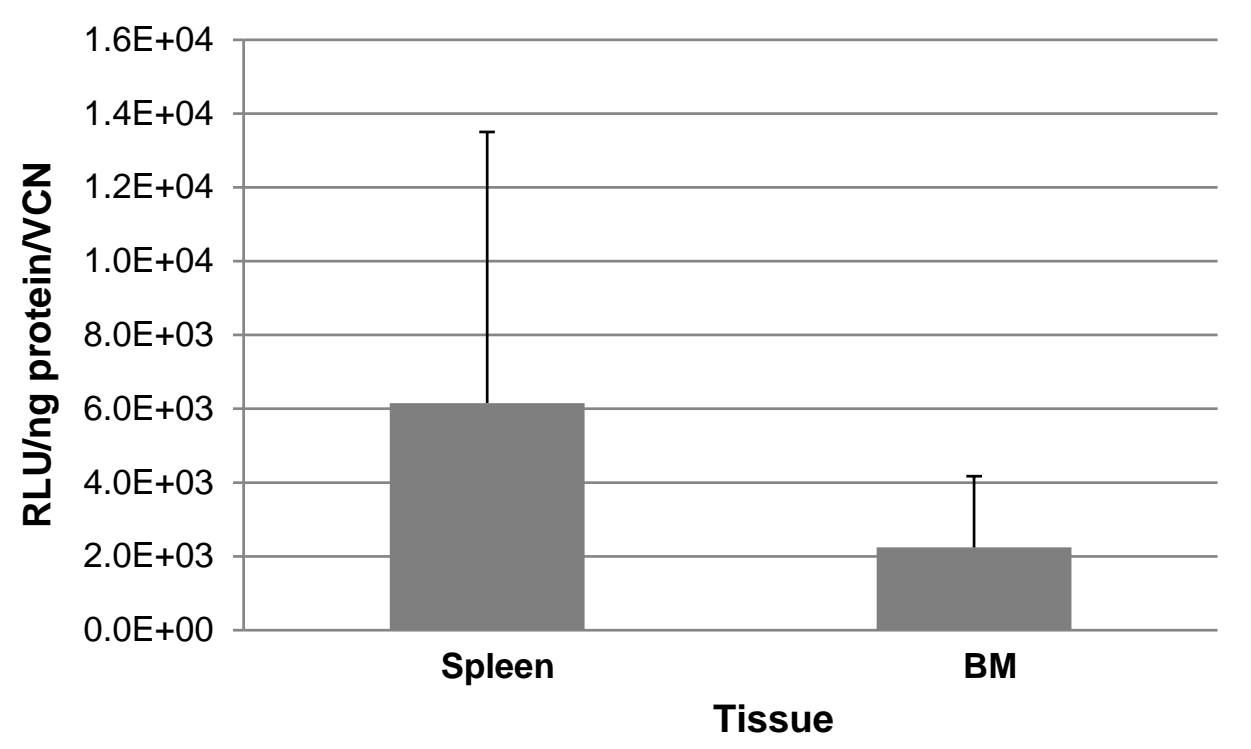


Figure 3

A
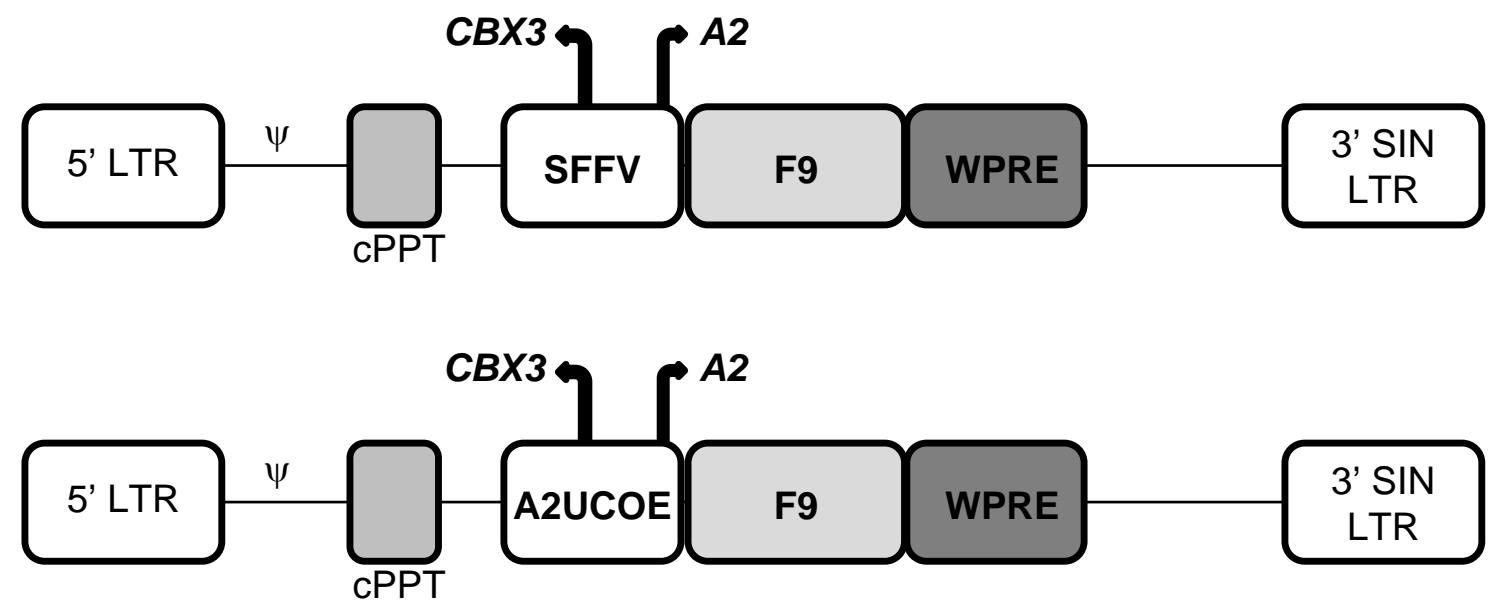

B SFFV-F9

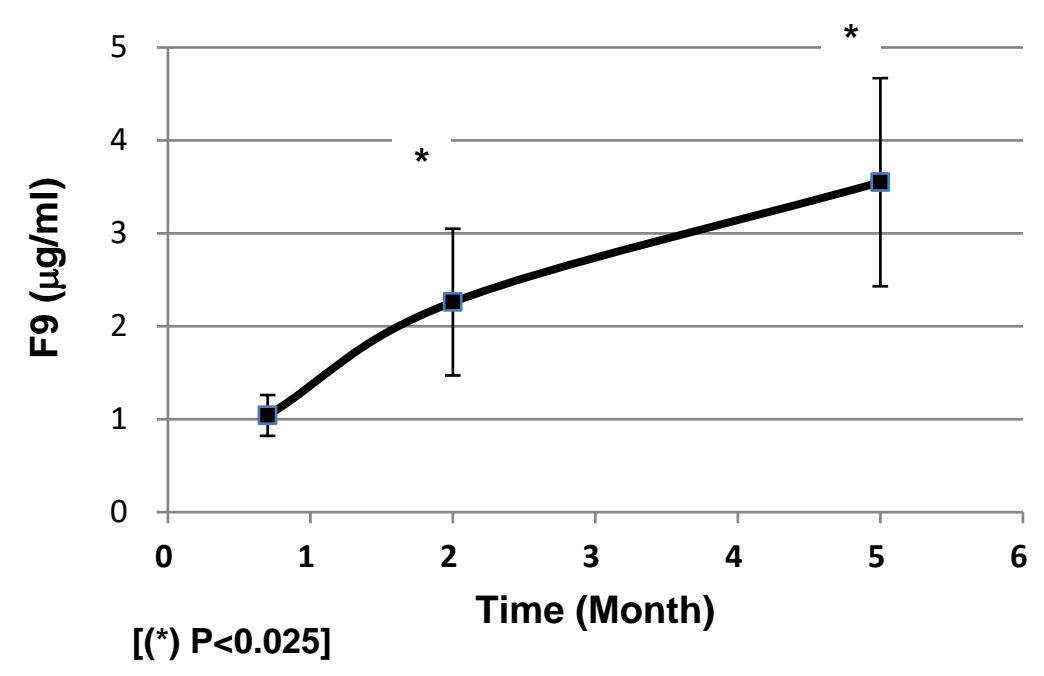

\begin{tabular}{c|ccc} 
Mouse & 0.7 Months & 2 Months & 5 Months \\
\hline SF-1 & $\mathrm{n} / \mathrm{a}$ & 2.99 & 4.77 \\
SF-2 & 1.17 & 2.65 & 3.81 \\
SF-3 & 1.00 & 2.16 & 4.68 \\
SF-4 & 0.75 & 0.76 & 3.36 \\
SF-5 & 1.24 & 2.33 & 2.79 \\
SF-6 & $\mathrm{n} / \mathrm{a}$ & 2.68 & 1.86 \\
\hline Average & & & \\
F9 & $\mathbf{1 . 0 4}$ & $\mathbf{2 . 2 6}$ & $\mathbf{3 . 5 5}$ \\
( $\mu$ g/ml) & & &
\end{tabular}

Weird that it rises. Maybe the reviewers will suggest tumors? Maybe leave it unanswered so that you can deny that in the reponse to reviewers? Also, it's not what we saw before....
All instances of F9 should be FIX (or ever hFIX) 
Figure 3

\section{A2UCOE-F9}

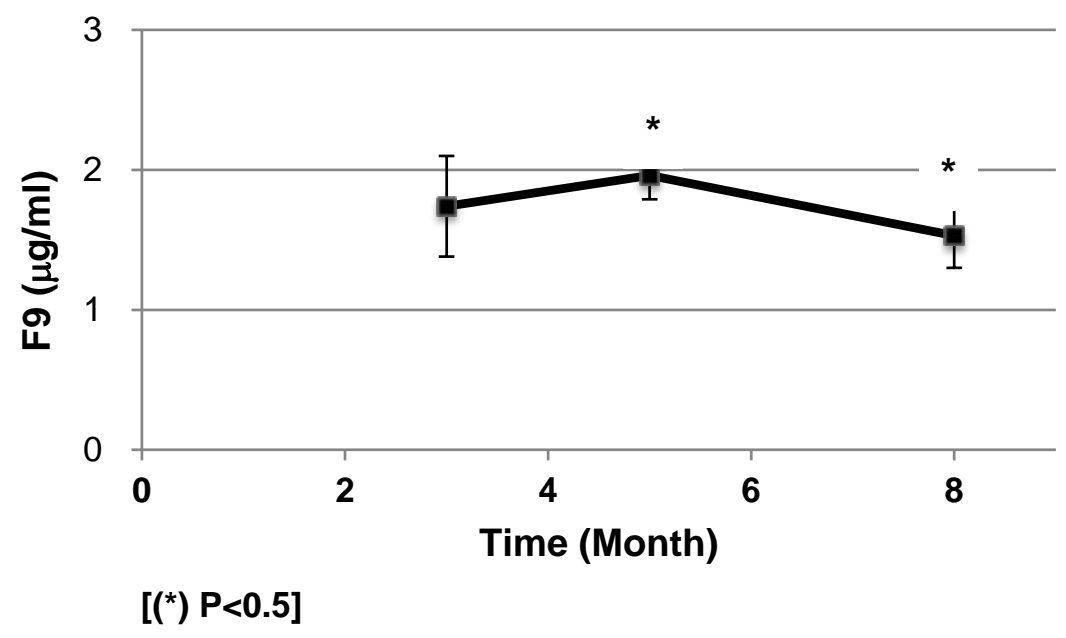

\begin{tabular}{c|ccc} 
Mouse & 3 Months & 5 Months & 8 Months \\
\hline UF-1 & 1.87 & 2.01 & 1.41 \\
UF-2 & 2.02 & 2.10 & 1.79 \\
UF-3 & 1.34 & 1.77 & 1.39 \\
\hline Average & \multirow{1}{*}{$\mathbf{2 4}$} & $\mathbf{1 . 9 6}$ & $\mathbf{1 . 5 3}$ \\
F9 $\boldsymbol{\mu g} / \mathrm{ml}$ & & &
\end{tabular}

All instances of F9 should be FIX (or even hFIX) 
Figure 4

\section{A $\quad$ SFFV-F9}

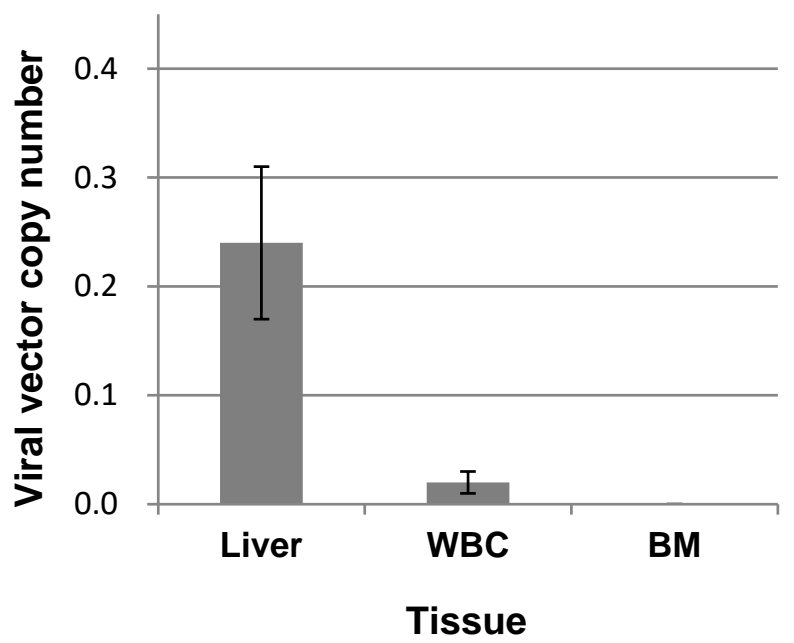

\begin{tabular}{c|ccc} 
Mouse & Liver & WBC & BM \\
\hline SF-1 & 0.39 & 0.00 & 0.00 \\
SF-2 & 0.28 & 0.03 & 0.00 \\
SF-3 & 0.26 & 0.30 & 0.00 \\
SF-4 & 0.17 & 0.03 & 0.01 \\
SF-5 & 0.34 & 0.02 & 0.00 \\
SF-6 & 0.17 & 0.01 & 0.00 \\
\hline Average & $\mathbf{0 . 2 4}$ & $\mathbf{0 . 0 2}$ & $\mathbf{0 . 0 0}$ \\
VCN & & &
\end{tabular}

\section{B A2UCOE-F9}

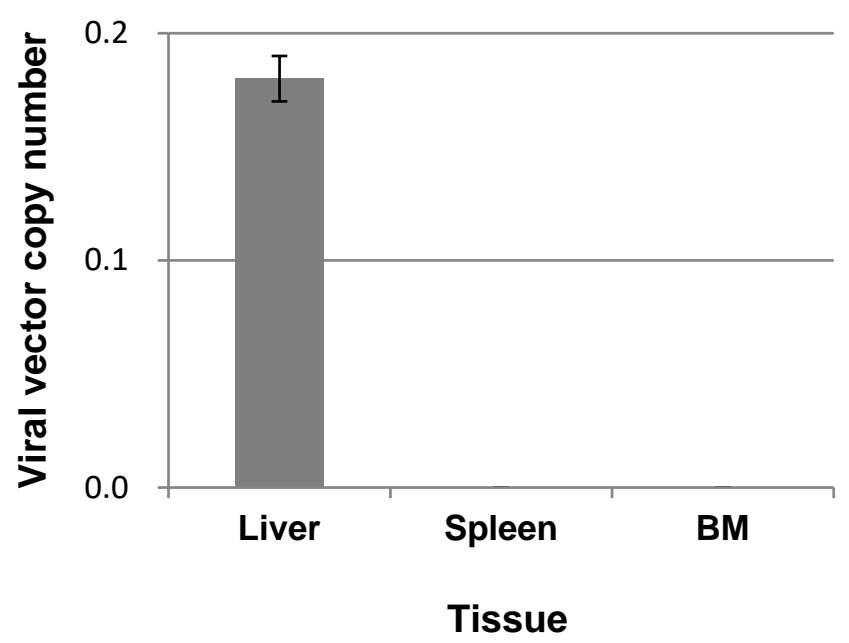

\begin{tabular}{c|ccc} 
Mouse & Liver & WBC & BM \\
\hline UF-1 & 0.21 & 0.00 & 0.00 \\
UF-2 & 0.19 & 0.00 & 0.00 \\
UF-3 & 0.17 & 0.00 & 0.00 \\
\hline $\begin{array}{c}\text { Average } \\
\text { VCN }\end{array}$ & $\mathbf{0 . 1 8}$ & $\mathbf{0 . 0 0}$ & $\mathbf{0 . 0 0}$
\end{tabular}

All instances of F9 should be FIX (or even hFIX) 
Figure 4

C

\begin{tabular}{c|c|c|c} 
Mouse & SFFV & mouse & A2UCOE \\
\hline SF-1 & 8.04 & UF-1 & 32.62 \\
SF-2 & 6.37 & UF-2 & 37.63 \\
SF-3 & 6.96 & UF-3 & 28.53 \\
SF-4 & 11.40 & & \\
SF-5 & 5.05 & & \\
SF-6 & 6.12 & & \\
\hline $\begin{array}{c}\text { Average F9 } \\
\text { ng/ } / \text { g } \\
\text { protein/ } \\
\text { VCN }\end{array}$ & $\mathbf{7 . 3 2}$ & Average & $\mathbf{3 2 . 9 3}$ \\
\hline
\end{tabular}

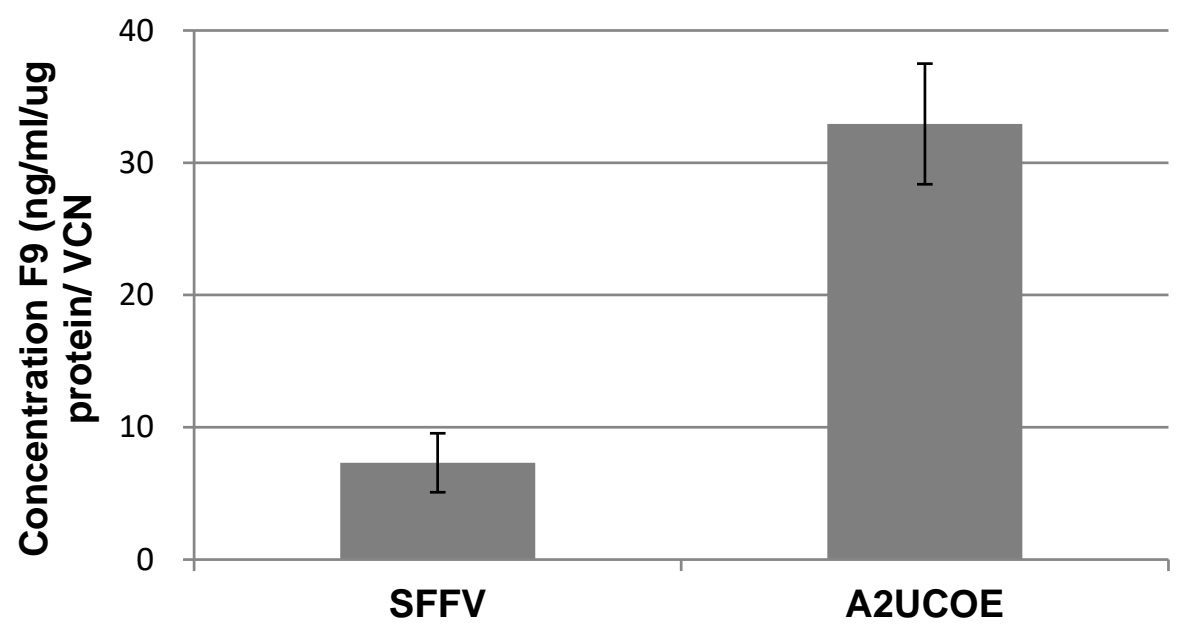

